\title{
QuEChERS Method Development for Bio-monitoring of Low Molecular Weight Polycyclic Aromatic Hydrocarbons in South African Carp Fish using HPLC-fluorescence: An Initial Assessment
}

\author{
Afolake Olufunmilola Oduntan ${ }^{\mathrm{a}}$, Nikita Tawanda Tavengwa ${ }^{\mathrm{a}}$, Ewa Cukrowska ${ }^{\mathrm{a}}$, \\ Sabelo Dalton Mhlanga ${ }^{\mathrm{b}}$ and Luke Chimuka, ${ }^{\mathrm{a}, \mathrm{t}}$ \\ ${ }^{a}$ Molecular Sciences Institute, School of Chemistry, University of Witwatersrand, Private Bag 3, Johannesburg, 2050, South Africa. \\ ${ }^{b}$ Nanotechnology and Water Sustainability Research Unit, College of Science Engineering and Technology, University of South Africa, \\ Florida, Johannesburg, 1709, South Africa.
}

Received 7 October 2015, revised 29 December 2015, accepted 6 April 2016.

\begin{abstract}
Matrix components in the analysis of polycyclic aromatic hydrocarbons (PAHs) in fish require analytical methods with high selectivity and sensitivity. A quick, easy, cheap, effective, rugged and safe (QuEChERS) sample treatment method was optimized and applied, using HPLC-fluorescence for quantification of five low molecular weight PAHs: naphthalene (Nap), acenaphthene (Ace), phenathrene (Phe), fluoranthene (Flu) and pyrene (Pyr) in muscle of carp fish. Important in this study was the testing of different sorbents for clean-up in QuEChERS and comparison with Soxhlet extraction. Polymers and magnetite modified with $\gamma$-methacryloxypropyltrimethoxysilane ( $\gamma$-MPS) were equally as selective towards PAHs as primary secondary amine (PSA) and multiwalled carbon nanotubes were the least selective. The concentration of PAHs in carp fish from Hartebeespoort Dam using QuEChERS extraction method was comparable to Soxhlet extraction and ranged from $0.8-739 \mu \mathrm{g} \mathrm{kg}^{-1}$. In this study, the minimum concentration of PAHs in carp fish was $0.8 \mu \mathrm{g} \mathrm{kg}^{-1}$ for fluoranthene and the maximum was $739 \mu \mathrm{g} \mathrm{kg}^{-1}$ for Ace using QuEChERS method. The study revealed that polymers and magnetite modified with $\gamma$-MPS could be used as alternative clean-up sorbent in QuEChERs and that the concentration of PAHs in carp fish in the dam are a source of concern.
\end{abstract}

KEYWORDS

QuEChERS, PAHs, carp fish, HPLC-fluorescence, sorbents, selectivity.

\section{Introduction}

PAHs are a large group of semi-volatile organic compounds consisting of fused aromatic rings in linear, angular or clustered arrangements. ${ }^{1}$ They are lipophilic and have a high affinity for organic matter. ${ }^{2}$ They can also penetrate biological membranes, making them bio-available, and bio-accumulate in fish and other marine organisms through the food chain..$^{3-8}$

Excluding smokers and occupationally exposed populations, most individuals are exposed to PAHs predominantly from dietary sources such as fish. ${ }^{9}$ In 1995, PAHs were included to the list of hazardous substance by the Agency for Toxic Substances and Disease Registry (ATSDR) and the United States Environmental Protection Agency (USEPA). USEPA has identified 16 unsubstituted PAHs as priority pollutants. It is against this background that their distribution in the environment as potential risks to human health has been the focus of much attention. ${ }^{10}$ PAHs are an important concern due to their mutagenic and carcinogenic properties to humans and animals. ${ }^{11}$ In light of these concerns, evaluation of PAHs levels in fish muscle is an important objective for environmental and health sciences.

Isolation of PAHs from biological matrices most often involves complicated extraction and clean-up procedures to provide extracts ready for the accurate analytical determination. ${ }^{12}$ Sample preparation processes, therefore, have a direct impact on the accuracy, precision and quantification limits, and they are often a limiting step for many analytical methods. ${ }^{13}$ Considering

* To whom correspondence should be addressed. E-mail: luke.chimuka @ wits.ac.za low concentration levels of PAH residues in food matrices, the determination of these residues often requires extensive sample extraction from environmental samples and purification prior to analysis. For complex matrices, an extraction and clean-up steps is generally required. ${ }^{14}$ Techniques for PAH sample preparation include Soxhlet extraction, microwave assisted extraction, ${ }^{15}$ ultrasonic extraction, ${ }^{16}$ pressurized fluid extraction, ${ }_{1}^{17}$ pressurized hot water extraction, ${ }^{18}$ supercritical fluid extraction, ${ }^{19}$ and QuEChERS (Quick, Easy, Cheap, Effective, Rugged and Safe). ${ }^{20-22}$

The QuEChERS extraction technique is known to utilize a minimal amount of solvent and it also uses less time. The QuEChERS extraction method originally developed was introduced by Anastassiades et al. ${ }^{23}$ for extraction of a wide range of pesticides in fruit and vegetables. This technique has been used for the determination of a wide spectrum of analytes from different matrices such as pesticides and metabolites from meat-based baby food, ${ }^{24}$ PAHs from tea, ${ }^{25}$ simultaneously determination of pesticide and PAHs in fresh herbs. ${ }^{20}$

Few studies have been done on the risk assessment of PAHs in South African aqueous environmental compartments. ${ }^{26,27}$ Most of the analyses of PAHs in the South African environment have focused on sediment and soil samples. ${ }^{27-29}$ In this study, a QuEChERS extraction method was developed and optimized for the extraction of five PAHs: Nap (naphthalene), Ace (acenaphthene), Phe (phenathrene), Flu (fluoranthene) and Pyr (pyrene). These pollutants were extracted from carp fish from 
Hartebeespoort Dam (HPB) in Johannesburg West. The optimized parameters were the extraction speed, extraction time, volume of solvent, type of solvent, mass of salt $\left(\mathrm{MgSO}_{4}\right)$, the mass of fish used for extraction, mass of sorbent primary secondary amine (PSA). Other sorbents were also investigated for selectivity of PAHs from carp fish. The optimized QuEChERS extraction method was then applied for the analysis of PAHs in carp fish samples.

\section{Materials and Methods}

\subsection{Chemicals and Instrumentation}

All PAHs used, namely naphthalene (99.9\%), acenapthene (99.9\%), phenanthrene (99.9\%), fluoranthene (99.9\%) and pyrene $(99.9 \%$ ) were purchased from Sigma-Aldrich (Steinhein, Germany). Acetone (99\%) was purchased from Fischer Scientific (Loughborough, UK), while acetonitrile (99.9\%) was obtained from Sigma-Aldrich (Steinheim, Germany). Hexane (99.5\%), ethyl acetate $(99 \%)$ and dichloromethane $(99.5 \%)$ were purchased from Fluka (Steinheim, Germany). Magnesium sulphate was obtained from Sigma-Aldrich (Steinheim, Germany) and sodium chloride analytical grade was obtained from Merck KGaA (Darmstadt, Germany). For clean-up, $100 \mathrm{~g}$ of primary secondary amine (PSA) bonded with silica was purchased from Sulpeco (Bellefonte, USA). Methacryloxypropyltrimethoxysilane $(\gamma$-MPS)-coated magnetite, molecularly imprinted polymers (MIPs) and non-molecularly imprinted polymers (NIPs) were synthesized in our laboratory. ${ }^{30,31}$ Carbon nanotubes (CNTs) were obtained readily synthesized from Mhlanga et al. ${ }^{32}$ All reagents were used without any further purification. QuEChERS materials, Agilent SampliQ QuEChERS Kits were purchased from Agilent Technologies (Santa Clara, CA, USA).

An HPLC-fluorescence was used for the quantification of PAHs. HPLC system consisted of a Waters HPLC pump (Milford, Massachusetts) connected to a fluorescence detector. The

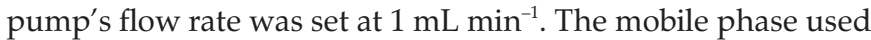
was acetonitrile/water $(80 / 20, \mathrm{v} / \mathrm{v})$. This was connected to RF-10AXL Shimadzu fluorescence detector (Kyoto, Japan) and clarity software purchased from Prodohradska (Prague, Czech). Excitation and emission wavelengths for HPLC-fluorescence were set as follows: Nap (280 nm and $490 \mathrm{~nm})$, Phe (225 nm and $460 \mathrm{~nm}), \operatorname{Pyr}(333 \mathrm{~nm}$ and $390 \mathrm{~nm})$, Ace (280 nm and $490 \mathrm{~nm})$ and Flu (290 nm and $320 \mathrm{~nm}) .100 \mu \mathrm{L}$ syringes obtained from Supelco Analytical (Pennsylvania, USA) were used for HPLC manual injections in a $20 \mu \mathrm{L}$ loop. The centrifuge used was an S-8 centrifuge obtained from Boeco (Hamburg, Germany). A 460 Elma ultrasonic bath (Elma, Germany) was used for removal of bubbles from mobile phase and for dissolving PAH standards.

\subsection{Sampling Sites}

Carp fish samples were obtained from local fishermen at Hartbeespoort Dam $\left(25.7475^{\circ} \mathrm{S}, 27.8669^{\circ} \mathrm{E}\right)$ in Gauteng Province. Fish samples were kept in a cool box and transported to the laboratory where they were frozen until analysis. Hartbeespoort Dam was chosen because it receives water from Jukskei River that passes through major industrial and residential areas to the south of Johannesburg city. The biggest wastewater treatment plant in the city also pumps its treated water in this river upstream. Thus the river and in turn the dam are regarded as one of the most polluted in the country. ${ }^{15}$

\subsection{Preparation of Stock and Calibration Solutions}

$1000 \mathrm{mg} \mathrm{L}^{-1}$ stock solution of PAHs was prepared by dissolving $50 \mathrm{mg}$ of PAHs in acetonitrile. The volume was diluted to the
$50 \mathrm{~mL}$ mark with acetonitrile for HPLC-fluorescence analysis. A $10 \mathrm{mg} \mathrm{L}^{-1}$ mixture stock solution was prepared from the $1000 \mathrm{mg}$ $\mathrm{L}^{-1}$ by withdrawing $100 \mu \mathrm{L}$ from the $1000 \mathrm{mg} \mathrm{L}^{-1}$ into a $10 \mathrm{~mL}$ volumetric flask, thereafter, the flask was filled to mark with acetonitrile. The calibration standards were then prepared from the mixture of PAHs in acetonitrile in the range of $0.01-0.1 \mathrm{mg} \mathrm{L}^{-1}$ for HPLC-fluorescence analysis. The calibration curve gave a good level of linearity with a correlation coefficient $\left(R^{2}\right)$ between 0.9585 and 1.000 (Table 1). The limit of detection of the PAHs in fish samples ranged from $0.2-1.1 \mu \mathrm{g} \mathrm{kg}^{-1}$.

Table 1 HPLC-fluorescence calibration curve.

\begin{tabular}{lrrrc}
\hline PAH & $R^{2}$ & Slope & Intercept & LOD $/ \mu \mathrm{gg}^{-1}$ \\
\hline Nap & 0.9585 & 35208 & 3972 & 0.2 \\
Ace & 0.9998 & 21062 & 3548.6 & 1.1 \\
Phen & 1.0000 & 7902 & 1843.3 & 1.1 \\
Flu & 1.0000 & 207219 & 131.9 & 0.2 \\
Pyr & 0.9954 & 3402 & 513.7 & 0.7 \\
\hline
\end{tabular}

\subsection{Sample Preparation and Optimization for the QuEChERS Technique}

The carp fish samples were eviscerated and filleted. Fish muscles were homogenized using a mortar and stored in a foil wrap and kept frozen until analysis. The QuEChERS extraction method was done using the procedure reported by Ramalhosa et al. ${ }^{33}$ In brief, a $2.5 \mathrm{~g}$ of fish sample was weighed in a $25 \mathrm{~mL}$ Teflon tube and spiked with $0.13 \mathrm{mg} \mathrm{L}^{-1}$ of $10 \mathrm{mg} \mathrm{L}^{-1}$ standard of the five PAHs. The spiked sample was mixed and allowed to stand for $30 \mathrm{~min}$ and then $10 \mathrm{~mL}$ of acetonitrile was added and shaken vigorously for $1 \mathrm{~min}$. This was followed by the addition of $2 \mathrm{~g}$ of $\mathrm{MgSO}_{4}$ and $0.5 \mathrm{~g}$ of $\mathrm{NaCl}$ salt into the tube, and the mixture was shaken vigorously for $1 \mathrm{~min}$ and then centrifuged. After centrifugation, $5.5 \mathrm{~mL}$ of sample was collected and $150 \mathrm{mg}$ PSA and $2 \mathrm{~g}$ of $\mathrm{MgSO}_{4}$ was added for clean-up. The sample was centrifuged for 5 min before filtering using a $0.45 \mu \mathrm{m}$ PTFE and injected in the GC-FID for analysis. For optimization, parameters that affected extraction, such as centrifugation time (10-30 min), centrifugation speed (3400-6000 rpm), type of solvent (ethylacetate, acetone and acetonitrile), fish mass (0.5-2.5 g), amount of salt (1.0-2.5 g) and volume of solvent $(6-10 \mathrm{~mL})$ were investigated in that order and the experiments were done in triplicate. As a clean-up sorbent, the same procedure as above was followed but instead of PSA other sorbents were investigated: molecular imprinted polymers (MIP), non-imprinted polymers (NIP), $\gamma$-MPS magnetite (MAG) and carbon nanotubes (CNTs).

\subsection{Soxhlet Extraction Procedure}

Homogenized fish samples as described above were Soxhlet extracted using method previously reported (US EPA, 1996C). Fish samples (15 g) were weighed in triplicate and spiked with different concentrations of PAHs ranging from 0.5, 1.0 and $1.5 \mu \mathrm{g} \mathrm{g}^{-1}$. Spiked fish sample were placed in a Soxhlet thimble and mixed with $15 \mathrm{~g}$ of $\mathrm{MgSO}_{4}$. Fish samples were extracted using $200 \mathrm{~mL}$ of dichloromethane/acetone $(1 / 1, \mathrm{v} / \mathrm{v})$ ratio for $20 \mathrm{~h}$ at a temperature of $35^{\circ} \mathrm{C}$. After extraction, the solvent was evaporated to $5 \mathrm{~mL}$ by a rotary evaporator and was made up to $10 \mathrm{~mL}$ with hexane and then further evaporated under nitrogen to $2 \mathrm{~mL}$. Extract was passed through a homogenized column consisting of $3 \mathrm{~g}$ of silica and $2 \mathrm{~g}$ of $\mathrm{Na}_{2} \mathrm{SO}_{4}$ which had been previously dried. Dichloromethane/hexane $(2 / 8, v / v)$ was used to elute the compounds from the column and solvent was evapo- 
rated to dryness under a gentle steam of nitrogen. A volume of $3 \mathrm{~mL}$ of acetonitrile was then added and $20 \mu \mathrm{L}$ of extract was injected into HPLC-fluorescence.

\section{Results and Discussion}

\subsection{Optimization of the QuEChERS Method}

The results obtained (Fig. 1a) when centrifugation time was varied while keeping all other parameters constant. Since the recoveries were almost independent of time (in the investigated time range), the least time was selected as the optimum. This was based on the economical motivation and $10 \mathrm{~min}$ was chosen as the optimal time for centrifuge. The extraction process is governed by a mass transfer which is time-dependent. ${ }^{34}$ Extraction process in QuEChERS is generally regarded as fast. Ramalhosa et $a .^{33}$ studied recovery of PAHs from fish sample using ultrasonic bath by increasing extraction time from 3 to $20 \mathrm{~min}$, and found $20 \mathrm{~min}$ to be optimum. Centrifuge time was also investi- gated by Keegan et al..$^{35}$ and 10 min was found to give optimum recovery. The optimum time of $10 \mathrm{~min}$ found in this study was therefore consistent with other previous studies.

From the investigation of centrifuge speeds (Fig. 1b), there was not much variation in recovery as the centrifuge speed was increased from 3400 to $5000 \mathrm{rpm}$. Centrifuging allows the solvent to be in contact with the sample, therefore making it to be more effective in dissolution of analyte. ${ }^{36}$ The centrifuge speed can reduce the time needed for extraction. ${ }^{37}$ Rodrigues et al. ${ }^{38}$ applied centrifuge speed of $5000 \mathrm{rpm}$ for the QuEChERS extraction of pesticides. Herrero et al. ${ }^{39}$ and Lopes et al. ${ }^{40}$ also used centrifuge speeds of $5000 \mathrm{rpm}$. This shows that $5000 \mathrm{rpm}$ is the most commonly used. In this instance, as the speed was increased, most of the PAHs were recovered at $5000 \mathrm{rpm}$. Initially, the amount extracted increased with stirring speed as this enhanced the movement of the PAHs from the sample to the solvent. However, at too high stirring speed, the extraction of PAHs decreased because of generation of air bubbles. King et al. ${ }^{41}$ varied the
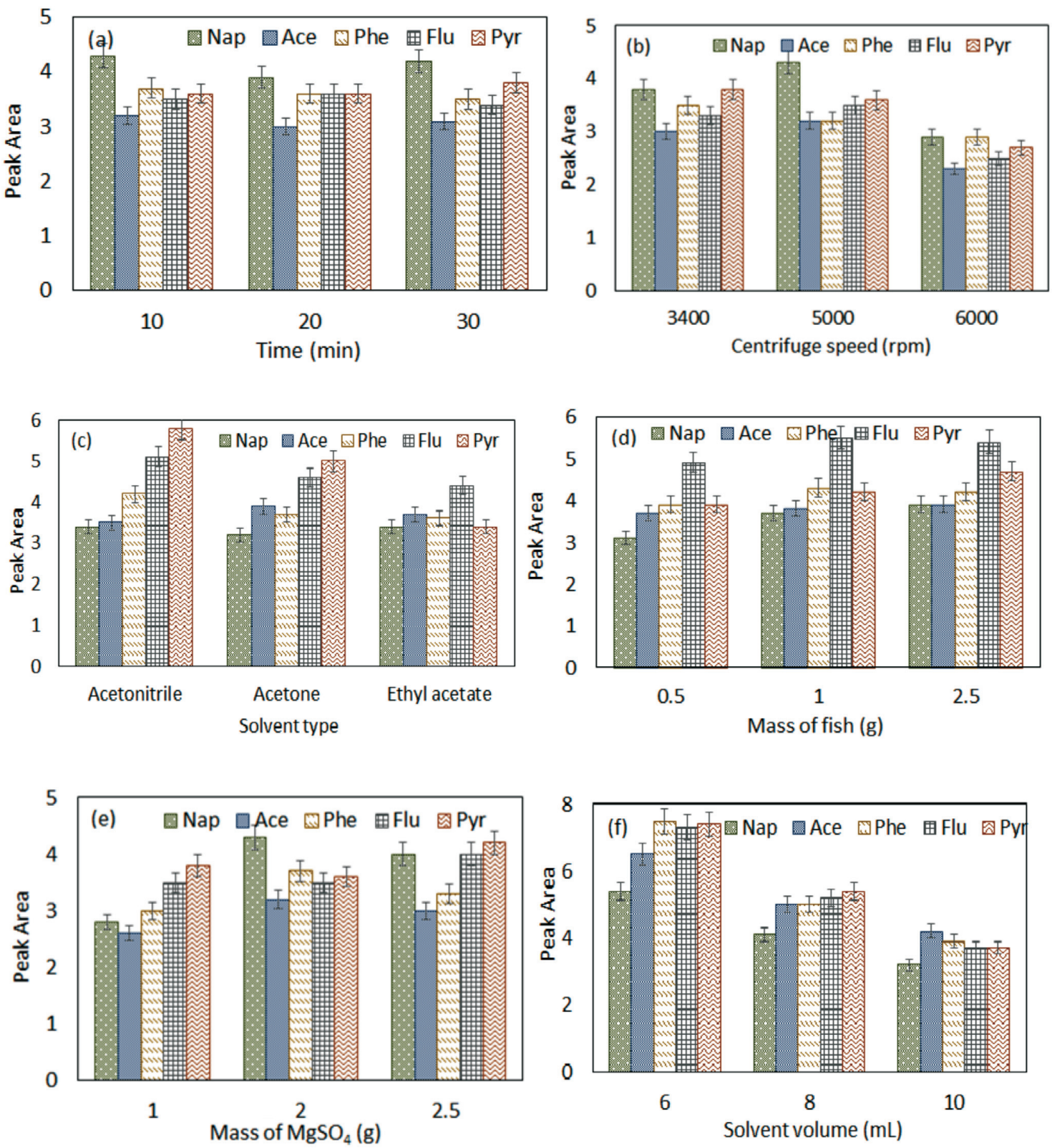

Figure 1 Effect of (a) centrifuge time, (b) centrifuge speed, (c) solvent type, (d) mass of fish, (e) mass of salt, and (f) solvent volume. [Experimental conditions: (a) $5000 \mathrm{rpm}, 8 \mathrm{~mL}$ acetonitrile, $2.5 \mathrm{~g}$ of fish, $2 \mathrm{~g} \mathrm{MgSO}_{4}, 0.5 \mathrm{NaCl}$ (b) $10 \mathrm{~min}, 8 \mathrm{~mL}$ acetonitrile, $2.5 \mathrm{~g}$ of fish, $2 \mathrm{~g} \mathrm{MgSO}_{4}, 0.5 \mathrm{NaCl}_{\text {(c) }} 10 \mathrm{~min}, 8 \mathrm{~mL}$ of the solvent, $2.5 \mathrm{~g}$ of fish, $2 \mathrm{~g} \mathrm{MgSO}_{4}, 0.5 \mathrm{NaCl}$ (d) $10 \mathrm{~min}, 8 \mathrm{~mL}$ acetonitrile, $2 \mathrm{~g} \mathrm{MgSO}_{4}, 0.5 \mathrm{NaCl}$ (e) $10 \mathrm{~min}, 8 \mathrm{~mL}$ acetonitrile, $2.5 \mathrm{~g}$ of fish, $0.5 \mathrm{NaCl}$ and (f) $10 \mathrm{~min}, 2.5 \mathrm{~g}$ of fish, $\left.2 \mathrm{~g} \mathrm{MgSO}_{4}, 0.5 \mathrm{NaCl}\right]$. 
stirring speed ( 0 to $1225 \mathrm{rpm}$ ) in their analysis of PAHs and also observed creation of air bubbles at over $800 \mathrm{rpm}$.

Acetonitrile and ethyl acetate have been widely used to extract polar to non-polar analytes ${ }^{42}$ and were tested together with acetone (Fig. 1c). Solvent type is very important when the QuEChERS method is developed. Pyr, Flu and Phe were better extracted using acetonitrile. Those slight differences reflect the type of intermolecular interaction that takes place between the PAHs and extraction solvent. PAHs are non-polar with mostly hydrophobic interactions through pi bonds being involved. This may explain why acetonitrile, also with pi bonds and linear in geometry, gave slightly better extractions. The structure of the solvent should allow maximum interactions with the analytes, besides its polarity. Acetonitrile separates more easily from water than other polar solvents used (acetone and ethyl acetate) in the QuEChERS method in the presence of salts. This gives a good phase separation which prevents interaction of polar matrix. ${ }^{43}$ Therefore, acetonitrile was chosen as the optimal solvent for extraction.

The results on the optimization of fish mass revealed that there was slight variation in the peak areas obtained (Fig. 1d). Overall, 1.0 and $2.5 \mathrm{~g}$ gave slightly higher peak areas than $0.5 \mathrm{~g}$. Homem $e t$ $a l .{ }^{44}$ investigated the mass to solvent volume ratio and observed that a ratio lower than $0.17 \mathrm{~g} \mathrm{~mL}^{-1}$ gave very low recoveries. In this study, solvent volume was kept at $10 \mathrm{~mL}$ and fish mass of 0.5 , 1.0 and $2.5 \mathrm{~g}$ were tested. This gave mass to solvent ratios of 0.05 , 0.1 and 0.25 , respectively. In this study, $2.5 \mathrm{~g}$ was used as optimum fish mass as this mass gave a slightly higher peak area.

The results obtained when the mass of $\mathrm{MgSO}_{4}$ was varied during the extraction showed that there was an increase in recovery of Nap, Ace and Phe with the use of $2 \mathrm{~g}$ of $\mathrm{MgSO}_{4}$ (Fig. 1e). Increase in salt allows greater phase separation but high salt level can also affect the effectiveness of the extraction system. ${ }^{45}$ The right combination of quantity of salt used in phase separation is important as it regulates the polarity of the mixture. $\mathrm{MgSO}_{4}$ removes a lot of water and the reaction is exothermic which can improve the process of extraction..$^{23}$ Addition of salt increases the temperature of the system, lowers activation energy and also decreases the viscosity of the solvent thereby increasing solvent matrix interaction. ${ }^{46}$ The result shows that the optimal mass of salt is $2 \mathrm{~g}$ as there is not much variation between the $2 \mathrm{~g}$ mass and the $2.5 \mathrm{~g}$ mass of salt.

A decrease in the amount extracted was observed with increase in volume of solvent (Fig. 1f). Decrease was more pronounced with $10 \mathrm{~mL}$. However, it can be noted that from recovery, 6 and $8 \mathrm{~mL}$ gave high recoveries. Homem et al. ${ }^{44}$ studied the effect of sample mass to solvent ratio on recovery. Optimum ratio obtained was 0.17 . In this study, the volumes used gave sample mass to volume of $0.41,0.31$ and 0.25 , respectively. Closest mass to solvent volume obtained by Homem et $a l .{ }^{44}$ was 0.25 which was equivalent to $10 \mathrm{~mL}$. Satisfactory recovery was obtained for $10 \mathrm{~mL}$ volume which ranged from 95 to $104 \%$ recovery as noted above, while for the 6 and $8 \mathrm{~mL}$ volume; recovery of Flu was $130 \%$ while in the $6 \mathrm{~mL}$ volume recovery of Phe exceeded $120 \%$. Larger recoveries may be due to matrix effect. $^{39,44}$ Thus $10 \mathrm{~mL}$ solvent volume was taken as optimum.

\subsection{Comparison of Different Sorbents}

The structures of the different sorbents are shown in Fig. 2 and their recoveries in QuEChERS method are compared in Fig. 3. After synthesis, the MIP and NIP were washed with distilled water to remove the unreacted pre-polymerization reagents before use. $\gamma$-MPS-coated magnetite was washed with water followed by methanol. Washing solutions were analyzed to check for any impurities. The recovery of PAHs from different sorbents showed that there was not much differences (Fig. 3). The selectivities of the different sorbents was tested by extracting unspiked samples (blank) of carp fish samples. Chromatograms (not presented) of extracts from various sorbents showed that CNTs gave the least selectivity. $\gamma$-MPS and polymer sorbents (MIP and NIP) gave slightly cleaner chromatograms followed by PSA. It should be noted that the MIP used were not specific for PAHs, and therefore acted as ordinary sorbent like the NIP. In this case, PSA was still taken as the best sorbent since recovery and selectivity was not that different from other sorbents. Generally, PSA is recommended for clean-up of sugars, organic acids and polar pigments.

\subsection{Comparison of Recoveries between QuEChERS and Soxhlet Extraction Methods}

Figure 4 shows the recoveries obtained for the QuEChERS and Soxhlet extraction methods at optimized conditions. As spiking concentrations were increased, the peak areas increased in both methods and recoveries obtained were independent of the spiking concentration. However, at lower concentration, the recoveries were higher than $100 \%$ for some analytes (Nap, Phe, Flu and Pyr) due to matrix effects. QuEChERS gave higher recovery for all the five PAHs than Soxhlet extraction. This was
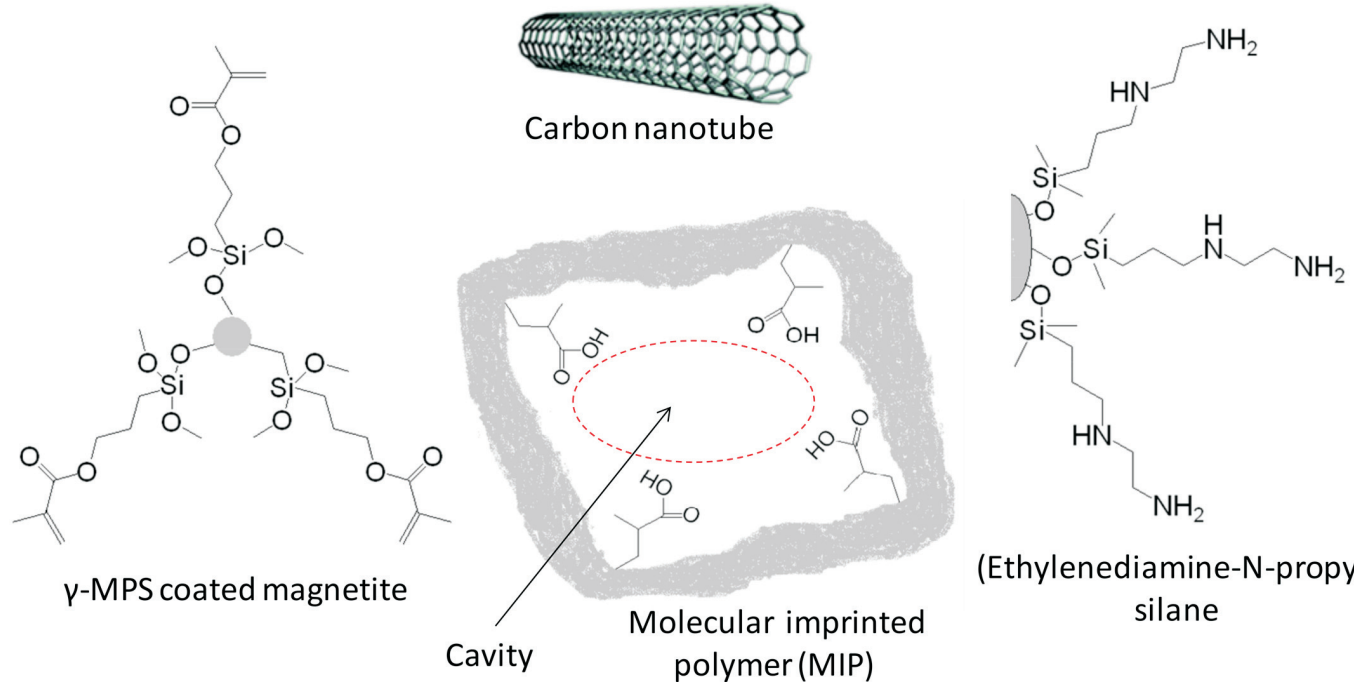

(Ethylenediamine-N-propyl) silane

Figure 2 Different sorbents used for the QuEChERS method. 


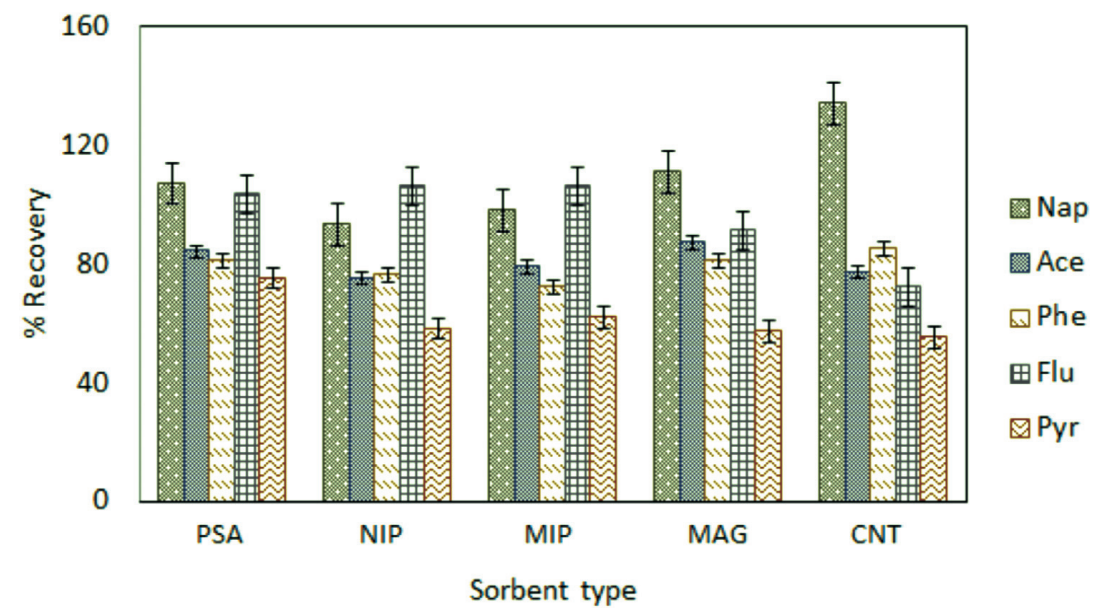

Figure 3 Comparision of recoveries obtained for different sorbent in QuEChERS extraction method $(n=3)$. [Experimental conditions: $2.5 \mathrm{~g}$ of fish, $10 \mathrm{~mL}$ acetonitrile, $2 \mathrm{~g} \mathrm{MgSO}_{4}, 0.5 \mathrm{~g}$ of $\mathrm{NaCl}$ and $\left.5000 \mathrm{rpm}\right]$.

expected as the latter has slow mass transfer and thus extraction takes hours compared to few minutes with QuEChERS, besides large amounts of solvents are consumed.

\subsection{Application of QuEChERS Method and Comparison with Soxhlet Exaction Method}

A typical chromatogram of a spiked fish sample obtained using HPLC-fluorescence is shown in Fig. 5. Table 2 shows the concentration levels of PAHs obtained in carp fish samples taken from Hartbeespoort Dam (HPB). Nap was not detected in all the samples by both methods. This might be due to variation in the possible sources of these compounds in the dam. Phe was detected in highest concentration in both methods followed by

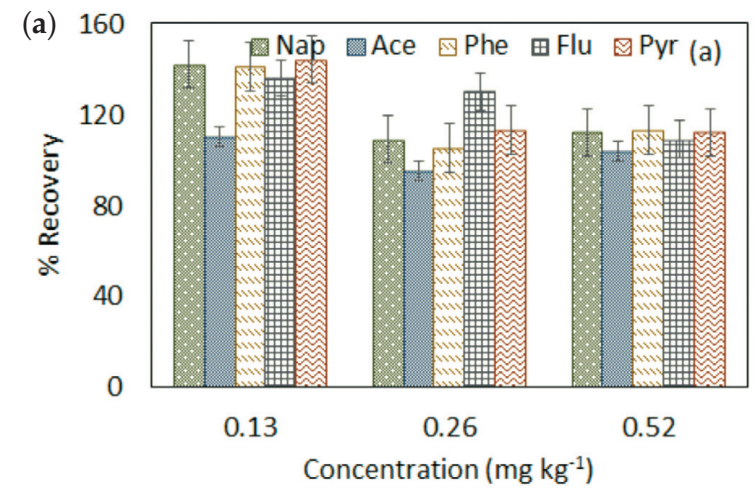

Ace, then Flu and Pyr. The results showed that there was no statistical difference between the Soxhlet extraction as compared to the QuEChERS method for the Ace and Flu ( $t_{\text {cal }}<t_{\text {table }}$ (2.447)). However, significant difference was found between the two methods for Phe and Pyr (Phe and Pyr $t_{\text {cal }}$ values of 7.132 and 5.808 , respectively were both $>t_{\text {table }}$ of 2.447 at $95 \%$ confidence interval). The explanation for this difference in the methods for Phe and Pyr can be attributed to matrix effects in the samples especially for Sohxlet extraction which is less selective compared to QuEChERS method. A plot (not shown) of concentration of PAHs against fish length for Pyr and Ace from Hartbeespoort Dam gave positive correlations $R^{2}=0.919$ and $R^{2}=0.773$, respectively. For other PAHs in fish samples, there was no positive

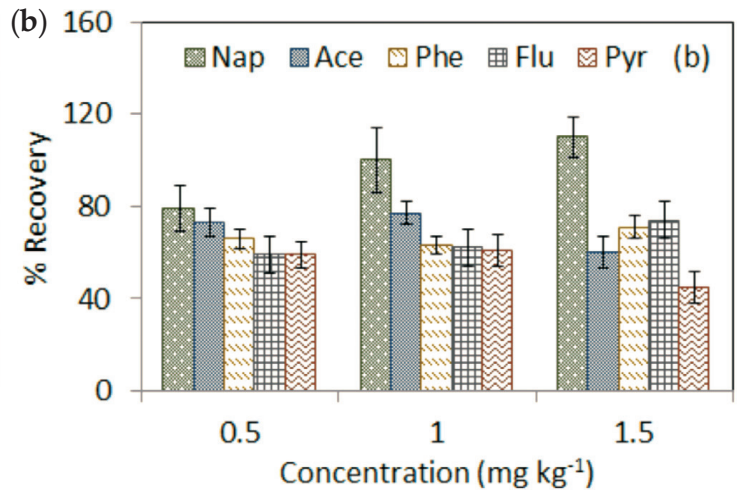

Figure 4 Recoveries of PAHs by (a) QuEChERS and (b) Soxhlet extraction $(n=3)$. [Experimental conditions: $2.5 \mathrm{~g}$ of fish, $10 \mathrm{~mL}$ acetonitrile, $2 \mathrm{~g} \mathrm{MgSO}$, $0.5 \mathrm{~g}$ of $\mathrm{NaCl}$ and $5000 \mathrm{rpm}]$.

Table 2 Concentration obtained from fish samples from Hartbeespoort dam in Gauteng using the QuEChERS and Soxhlet extraction methods $(n=3)$.

\begin{tabular}{|c|c|c|c|c|c|c|c|}
\hline \multirow[t]{2}{*}{ Sample site } & \multirow{2}{*}{$\begin{array}{l}\text { Fish length } \\
/ \mathrm{cm}\end{array}$} & \multirow{2}{*}{$\begin{array}{c}\text { Fish width } \\
/ \mathrm{cm}\end{array}$} & \multicolumn{5}{|c|}{ PAHs concentration $/ \mu \mathrm{g} \mathrm{kg}^{-1}$} \\
\hline & & & Nap & Ace & Phe & Flu & Pyr \\
\hline \multicolumn{8}{|c|}{ QuEChERS extraction method } \\
\hline HPB 1 & 21 & 7.0 & nd & $37.7(4.1)$ & $683.6(0.9)$ & $0.9(13.2)$ & $1.7(3.9)$ \\
\hline НРВ 2 & 22.4 & 7.6 & nd & $40.3(3.5)$ & $739.0(0.5)$ & $4.7(11.3)$ & $1.5(8.0)$ \\
\hline HРB 3 & 24.5 & 8.6 & nd & $38.1(1.6)$ & $717.2(4.9)$ & $3.7(8.6)$ & $1.7(5.3)$ \\
\hline HPB 4 & 35.5 & 12.5 & nd & $50.3(0.5)$ & $641.4(1.2)$ & $6.1(10.5)$ & $2.0(2.2)$ \\
\hline \multicolumn{8}{|c|}{ Soxhlet extraction method } \\
\hline НPB 1 & 21 & 7.0 & nd & $37.8(0.6)$ & $838.5(1.0))$ & $1.9(2.2)$ & $5.2(0.1)$ \\
\hline НРВ 2 & 22.4 & 7.6 & nd & $43.2(2.3)$ & $890.0(7.2)$ & $9.4(0.2)$ & $4.5(0.4)$ \\
\hline НРВ 3 & 24.5 & 8.6 & nd & $46.3(0.4)$ & $908.5(0.7)$ & $6.1(0.1)$ & $6.2(1.0)$ \\
\hline НРВ 4 & 35.5 & 12.5 & nd & $55.2(2.4)$ & $902.6(3.8)$ & $6.1(1.1)$ & $7.8(4.1)$ \\
\hline
\end{tabular}

Note: $\mathrm{nd}=$ not detected, standard deviations are in brackets. 


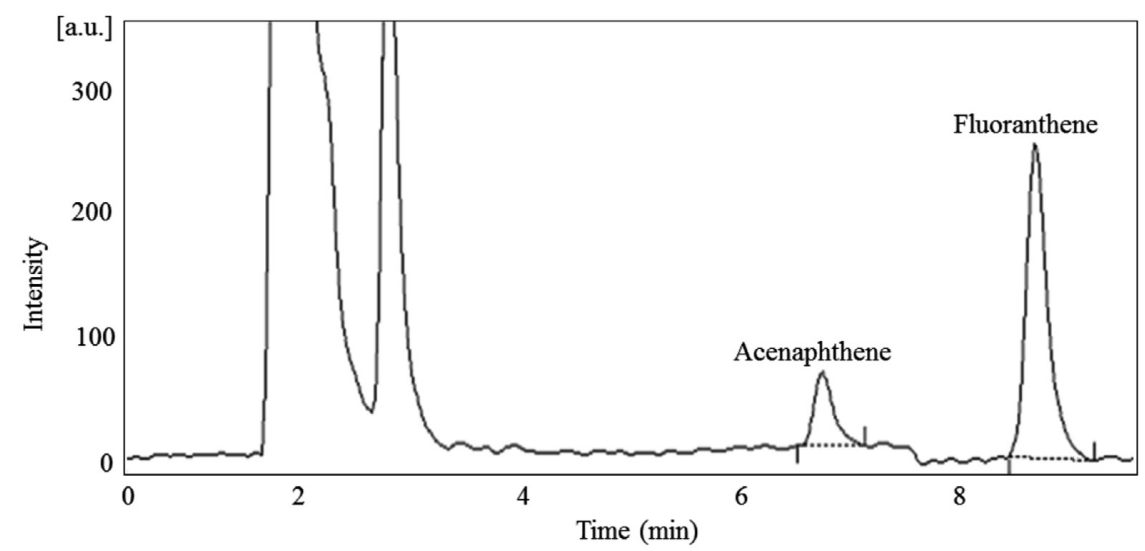

Figure 5 Chromatogram of an unspiked fish sample obtained from QuEChERS extraction method using HPLC-fluorescence.

correlation. These diffferences could be due to factors such as fish metabolism of the compounds, bioavailabilty of the compounds from the water which affects the their bioconcentration.

\section{Conclusions}

The results indicated that polymeric sorbents and $\gamma$-MPScoated magnetite can serve as good alternative to PSA as they gave comparable recovery and selectivity for PAHs in fish. QuEChERs method was found to be very efficient in extraction PAHs in fish compared to Soxhlet extraction as it was faster and gave better recoveries. The concentration of PAHs in fish samples from Hartesbeesport Dam found using QuEChERS method was comparable to Soxhlet extraction method though for some PAHs, the latter gave slightly higher results. Results of $\mathrm{PAH}$ concentration in fish samples from the dam indicate that the dam is acting as a sink for pollution occurring upstream and is a cause of concern. Further monitoring of substituted PAHs and all 16 US EPA listed PAHs is recommended.

\section{Acknowledgements}

This work was funded by the Water Research Commission (WRC) of South Africa, Project number K8-849.

\section{References}

1 E. Morillo, A.S. Romero, C. Maqueda, L. Madrid, F. Ajmone-Marsan, H. Grcman, C.M. Davidson, A.S. Hursthouse and J. Villaverde, Soil pollution by PAHs in urban soils: a comparison of three European cities, J. Environ. Monit., 2007, 9, 1001-1008.

2 M. Nadal, M. Schuhmacher and J.L. Domingo, Levels of PAHs in soil and vegetation samples from Tarragona County, Spain, Environ. Pollut., 2004, 132, 1-11.

3 A. Schecter, L. Birnbaum, J.J. Ryan and J.D. Constable, Dioxins: an overview, Environ. Res., 2006, 101, 419-428.

4 S. Boonchan, M.L. Britz and G.A. Stanley, Surfactant-enhanced biodegradation of high molecular weight polycyclic aromatic hydrocarbons by Stenotrophomonas maltophilia, Biotechnol. Bioeng., 1998, 59, 482-494.

5 I.N. Nasr, N.H.A. EL-Enaen and T.A. Yosef, Study of some polycyclic aromatic hydrocarbons residues in fish at Sharkia Governorate markets in relation to public health, Global Veterinaria, 2012, 8, 670-675.

6 J.S. Latimer and J. Zheng, The sources, transport and fate of PAHs in the marine environment, in PAH: An Ecotoxicological Perspective (P.E.T Douben, ed.), Wiley, Chichester, UK, 2003, pp. 9-33.

7 Y. Liang, M.F. Tse, L. Young and M.H. Wong, Distribution patterns of polycyclic aromatic hydrocarbons (PAHs) in the sediments and fish at Mai Po Marshes Nature Reserve, Hong Kong, Water Res., 2007, 41, 1303-1311.

8 M. Perugini, P. Visciano, A. Giammarino, M. Manera, W. Di Nardo and $\mathrm{M}$. Amorena, Polycyclic aromatic hydrocarbons in marine organisms from the Adriatic Sea, Italy, Chemosphere 2007, 66, 1904-1910.

9 L.R. Bordajandi, M. Dabrio, F. Ulberth and H. Emons, Optimisation of the GC-MS conditions for the determination of the $15 \mathrm{EU}$ foodstuff priority polycyclic aromatic hydrocarbons, J. Sep. Sci., 2008, 31, 1769-1778.

10 E. Manoli and C. Samara, Polycyclic aromatic hydrocarbons in waste waters and sewage sludge: extraction and clean-up for HPLC analysis with fluorescence detection, Chromatographia 1996, 43 , 135-142.

11 K. Li, H. Li, L. Liu, Y. Hashi, T. Maedac and J. Lin, Solid-phase extraction with C30 bonded silica for analysis of polycyclic aromatic hydrocarbons in airborne particulate matters by gas chromatography-mass spectrometry, J. Chromatogr. A 2007, 1154, 74-80.

12 R.E. Majors, New chromatography columns and accessories at the 2003 Pittsburg conference, Part II. LC GC Europe, 2003, 21, 332-348.

13 K.D. Bartle, in Food Contaminant, Sources and Surveillance (C.S. Creaser and R. Purchase, eds.), Royal Society of Chemistry, Cambridge, UK, 1991.

14 A. Lazartigues, L. Wies, R. Baudot, M. Thomas, C. Feidt and C. Cren-Olivé, Multi residue method to quantify pesticides in fish muscle by QuEChERS-based extraction and LC-MS/MS, Anal. Bioanal. Chem., 2011, 400, 2185-2193.

15 P. Sibiya, L. Chimuka, E. Cukrowska and H. Tutu, Development and application of microwave assisted extraction (MAE) for the extraction of five polycyclic aromatic hydrocarbons in sediment samples in Johannesburg area, South Africa, Environ. Monit. Assess., 2013, 185, 5537-5550.

16 D.R. Banjoo and P.K. Nelson, Improved ultrasonic extraction procedure for the determination of polycyclic aromatic hydrocarbons in sediments, J. Chromatogr. A 2005, 1066, 9-18.

17 S.D. Haskins, J.M. Duval, D.G. Kelly, S.L. Lundgreen-Nielsen and R.D. Weir, Pressurized fluid extraction of polycyclic aromatic hydrocarbons using silanized extraction vessels, Microchim. Acta, 2012, 178, 187-193.

18 T. Andersson, K.T.H. Hartonen and M.L. Riekkola, Pressurised hot water extraction and thermal desorption of polycyclic aromatic hydrocarbons from sediment with use of a novel extraction vessel, Anal. Chim. Acta 2002, 446, 93-100.

19 N. Cardellicchio, S. Cavalli and P. Ragone, Supercritical fluid extraction of polycyclic aromatic hydrocarbons (PAHs) in marine sediments and GC-MS analysis, Polycyclic Aromat. Compd., 1996, 9, 365-372.

20 A. Sadowska-Rociek, M. Surma and E. Cieślik, Application of QuEChERS method for simultaneous determination of pesticide residues and PAHs in fresh herbs, Bull. Environ. Contam. Toxicol., 2013, 90, 508-513.

21 A. Albinet, S. Tomaz and F. Lestremau, A really quick easy cheap effective rugged and safe (QuEChERS) extraction procedure for the analysis of particle-bound PAHs in ambient air and emission samples, Sci. Total Environ., 2013, 450-451, 31-38.

22 M. Andrascikova, S. Hrouzkova and S.C. Cunha, Combination of QuEChERS and DLLME for GC-MS determination of pesticide residues in orange samples, Food Addit. Contam., 2013, 30, 286-297

23 M. Anastassiades, S.J. Lehotay, D. Stajnbaher and F.J. Schenck, Fast and easy multi residue method employing acetonitrile extraction/partitioning and "dispersive solid-phase extraction" for the determination of pesticide residues in produce, J AOAC Int., 2003, 86, 412-431. 
24 C. Przybylski and C. Segard, Method for routine screening of pesticides and metabolites in meat based baby-food using extraction and gas chromatography-mass spectrometry, J. Sep. Sci., 2009, 32, 1858-1867.

25 A. Sadowska-Rociek, M. Surma and E. Cieślik, Comparison of different modifications on QuEChERS sample preparation method for PAHs determination in black, green, red and white tea, Environ. Sci. Poll. Res., 2014, 21, 1326-1338.

26 P. Sibiya, E. Cukrowska, J.Å. Jönsson and L. Chimuka, Development and application of solid phase extraction method for polycyclic aromatic hydrocarbons in water samples in Johannesburg area, South Africa, S. Afr. J. Chem., 2012, 65, 206-213.

27 S.K. Das, J. Routh and A.N. Roychoudhury, Sources and historic changes in polycyclic aromatic hydrocarbon input in a shallow lake, Zeekoevlei, South Africa, Org Geochem., 2008, 39, 1109-1112.

28 L. Quinn, R. Pieters, C. Nieuwoudt, A.R. Borgen, H. Kylin and H. Bouwman, Distribution profiles of selected organic pollutants in soils and sediments of industrial, residential and agricultural areas of South Africa, J. Environ. Monit., 2009, 11, 1647-1657.

29 C. Nieuwoudt, R. Pieters, L. Quinn, H. Kylin, A.R. Borgen and H. Bouwman, Polycyclic aromatic hydrocarbons (PAHs) in soil sediment from industrial, residential, and agricultural areas in central South Africa: an initial assessment, Soil Sediment Contam., 2011, 20, 188-204.

30 N.T. Tavengwa, E. Cukrowska and L. Chimuka, Preparation, characterization and application of $\mathrm{NaHCO}_{3}$ leached bulk U(VI) imprinted polymers endowed with $\gamma$-MPS coated magnetite in contaminated water, J. Hazard. Mater., 2014, 267, 221-228.

31 B. Mhaka, E. Cukrowska, S.B.B. Tse, O. Ramström, K. Haupt, H. Tutu and L. Chimuka, Selective extraction of triazine herbicides from food samples based on a combination of a liquid membrane and molecularly imprinted polymers, J. Chromatogr. A 2009, 1216, 6796-6801.

32 S.D. Mhlanga and N.J. Coville, Iron-cobalt catalysts synthesized by a reverse micelle impregnation method for controlled growth of carbon nanotubes, Diamond Relat. Mater., 2008, 17, 1489-1493.

33 M.J. Ramalhosa, P. Paiga, S. Morias, C. Delerue-Matos, M.B. Oliveira, Analysis of polycyclic aromatic hydrocarbons in fish: evaluation of a quick, easy, cheap, effective, rugged, and safe extraction method, J. Sep. Sci., 2009, 32, 3529-3538.

34 C. Basheer, R. Balasubramanian and H.K. Lee, Determination of organic micropollutants in rainwater using hollow fiber membrane/liquid-phase microextraction combined with gas chromatography-mass spectrometry, J. Chromatogr. A 2003, 1016, 11-20.

35 J. Keegan, M.D. Whelan, S. Crooks, R. Sayers, A. Anastasio, C. Elliott, D. Brandon, A. Furey and R. O'Kennedy, Benzimidazole carbamate residues in milk: detection by surface plasmon resonance-biosensor, using a modified QuEChERS (Quick, Easy, Cheap, Effective, Rugged and Safe) method for extraction, Anal. Chim. Acta 2009, 654,111-119.

36 A. Kouzayha, M.A. Iskandarani, S. Mokh, A.R. Rabaa, H. Budzinski and F. Jaber, Optimization of a solid-phase extraction method using centrifugation for the determination of 16 polycyclic aromatic hydrocarbons in water, J. Agric. Food. Chem., 2011, 59, 7592-7600.

37 D. Bai, J. Li, S.B. Chen and B.H. Chen, A novel cloud-point extraction process for preconcentrating selected polycyclic aromatic hydrocarbons in aqueous solution, Environ. Sci. Technol., 2001, 35, 3936-3940.

38 S.A. Rodrigues, S.S. Caldas, M.H.S. Kurz, L.D Cabrera, F.A. Duarte, R. Zanella and E.G. Primel, Comparison of matrix solid-phase dispersion and modified QuEChERS methods for extraction of pesticide residues from onion, Anal. Methods, 2012, 4, 1820-1824.

39 M.S. Herrero, P.C. García, P.J.C. Pérez, V. Homem, J.A. Silva, C. Cunha, A. Alves and L. Santos, New analytical method for the determination of musks in personal care products by Quick, Easy, Cheap, Effective, Rugged, and Safe extraction followed by GC-MS, J. Sep. Sci., 2013, 36, 2176-2184.

40 R.P. Lopes, R.C. Reyes, R. Romero-Gonzalez, A.G. Frenich and J.L. Vidal, Development and validation of a multiclass method for the determination of veterinary drug residues in chicken by ultra-high performance liquid chromatography-tandem mass spectrometry, Talanta 2012, 89, 201-208.

41 S. King, J.S. Meyer and A.R.J. Andrews, Polycylic aromatic hydrocarbons in soil using hollow fiber membrane solvent microextraction, J. Chromatogr. A 2002, 982, 201-208.

42 R. Carabias-Martinez, E. Rodriguez-Gonzalo, P. Revilla-Ruiz and J. Hernandez-Mendez, Pressurized liquid extraction in the analysis of food and biological samples, J. Chromatogr. A 2005, 1089, 1-17.

43 C. Diez, W.A. Traag, P. Zommer, P. Marinero and J. Atienza, Comparison of an acetonitrile extraction/partitioning and dispersive solidphase extraction method with classical multi-residue methods for the extraction of herbicide residues in barley samples, J. Chromatogr. A 2006, 1131, 11-23.

44 V. Homem, S.J. Avelino, C. Cunha, A. Alves and L. Santos, New analytical method for the determination of musks in personal care products by Quick, Easy, Cheap, Effective, Rugged, and Safe extraction followed by GC-MS, J. Sep. Sci., 2013, 36, 2176-2184.

45 E. Coelho, C. Ferreira and C.M.M. Almeida, Analysis of polynuclear aromatic hydrocarbons by SPME-GC-FID in environmental and tap waters, J. Braz. Chem. Soc., 2008, 19, 1084-1097.

46 B.E. Richter, B.A. Jones, J.L. Ezzell and N.L. Porter, Accelerated solvent extraction: a technique for sample preparation, Anal. Chem., 1996, 68, 1033-1039. 